\title{
Should you encourage students to assess themselves in practice learning? A guided self-efficacy approach to practice learning assessment
}

\section{Jonathan Parker ${ }^{1}$}

\begin{abstract}
Summary: Practice learning has assumed a place of central importance in the current qualifying education for social work in the UK. This paper seeks to explore whether students should be encouraged to contribute to the process of assessment and, assuming that they should, how this might be achieved. A self-efficacy model is proposed as a means of students assessing themselves and creating a constructive dialogue on their progress and development as beginning social workers.
\end{abstract}

Keywords: practice learning, assessment, self-assessment, self-efficacy

1. Professor of Social Work.

Address for Correspondence: Bournemouth University, Institute of Health and Community Studies, 4th Floor, Royal London House, Bournemouth BH1 3LT. parkerj@bournemouth.ac.uk 
A guided self-efficacy approach to practice learning assessment

\section{Introduction}

Practice learning opportunities, in general, are rigorously assessed and, indeed, always have been. Effective assessment demands that students know what is to be assessed and how it will be evaluated. Practice learning also requires students to become effective self-assessors, developing self-awareness, reflecting on learning, identifying needs and working out learning plans to meet them.

The changes wrought by the introduction of the new social work degree in England have a significant impact on practice learning. Indeed, the change in terminology from 'placement' to 'practice learning opportunity' reflects that significance, encouraging the exploration, development and implementation of innovative forms of learning to practise social work within the contemporary and complex world of public service. The extension of the number of days and structure of learning around two different service user groups in two distinct settings and including legal interventions is further evidence of that tumultuous change (Department of Health, 2002), which promotes opportunities to develop new approaches to practice learning and assessment (Parker, forthcoming). This paper explores whether students can and should be encouraged to assess themselves in practice learning, and, assuming that they can, to consider how practice teachers might assist in the process. This assumes great importance given the need to assist all practitioners undertaking new post-qualifying awards to contribute to the learning and education of others (GSCC, 2005). In doing so, research concerning self-efficacy will be introduced. It is postulated that self-efficacy measurement can be translated into a useful tool for guided self-assessment.

\section{The context of assessment and practice learning}

Practice teachers have a dual responsibility for making an assessment and a pass or fail recommendation to universities, as well as teaching and supporting students in their learning. At times, this has been seen as uncomfortable and producing a potential conflict of interests (Knight, 2003). It should not be seen in this way, however, as it is part of the learning and teaching process and perhaps reflects some of the changes required in practice teaching in social work (Watkins and Edwards, 2002). Assessment systems are complex and all those involved in the practice learning experience may be called upon to provide evidence of competence to practise (see figure 1). Gaining the views and opinions of all people involved with students can provide crucial

9 Journal of Practice Teaching 6(3) 2005, pp.8-30 $\quad$ (c) 2005 Whiting and Birch 
Figure 1

Sources of student assessment in practice

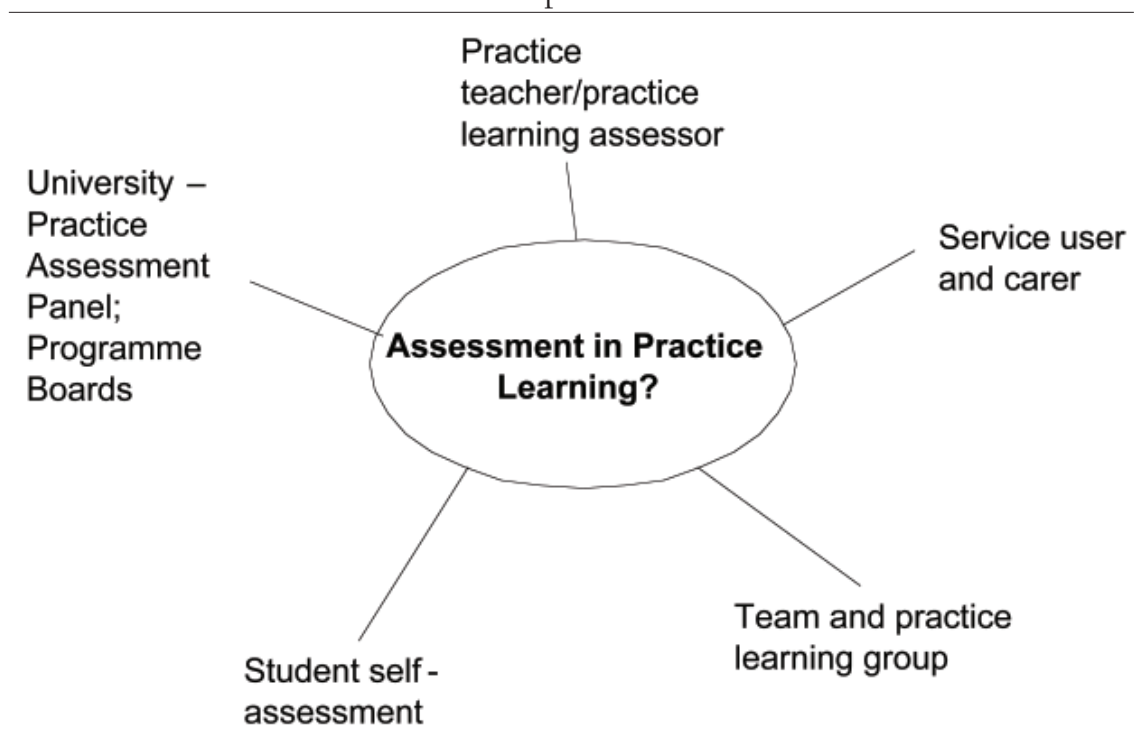

evidence in identifying learning needs and assessing competence. This includes feedback from team colleagues which may or may not be confirmatory but can be used and internalised to reframe learning objectives and contribute to the critical assessment process (Parker, 2004). Students may be involved in group or team learning and assessments (McCafferty, 2004) some of which may reflect agencies developing as learning organisations (SCIE, 2004) and developments in the organisation of practice learning (Parker, Whitfield and Doel, 2006). The perceptions and feedback from service users and carers (as those who receive the student's and agency's services, Doel and Shardlow, 2005; Edwards, 2003, Thomas, 2002), can again aid the focus on the learning needs and objectives to be negotiated and achieved through practice learning and evaluated within supervision. This mélange of evidence contributes to the process and assessment of learning following completion of the practice learning experience. Bruner (1966; cited in Ramsden, 2004, p. 223) states that:

(e)valuation is often viewed as a test of effectiveness - of materials, teaching methods, or what not - but this is the least important aspect of it. the most important is to provide intelligence in how to improve things.'

10 Journal of Practice Teaching 6(3) 2005, pp.8-30 (C) 2005 Whiting and Birch 
Students themselves are central to this assessment process, and critically reflective self-assessment can enhance it. If the focus of self-evaluation is on improvement of practice this can provide a useful process for practice assessors as well as their students.

\section{Can students assess themselves?}

When evaluating teaching practice in higher education, Ramsden (2004) suggests focusing on the following core areas:

- how others and how do you experience your practice as an educator

- evidence from as a wide a range of sources as possible (include users)

- a focus on improvement

- continuous and continuing process

Whilst these relate to the skills and performance of teachers in higher education, they can be applied to practice teacher and student self-assessment and form the basis of supervision sessions concerning the development of critical and reflective self-knowledge in practice. Supervision is a reciprocally developmental process and involves practice teachers evaluating their performance as well as the students theirs. As a process, it seems accepted that self-assessment is important in developing critical self-awareness, the skills of which are central to the human professions such as social work (Boud, 1995; Fitzpatrick, 2006). Taras (2003) indicates that this contributes to the learning process more when self-assessment is integrated with tutor feedback as an integrated process of learning and development. However, there is an on-going debate within higher education as a whole that questions whether students can evaluate their learning or practice and whether it is appropriate for students to assess themselves in more summative ways. In terms of the quality of the assessment, the criterion of 'fitness for purpose' - or does it test what it purports to test - holds good and using Ramsden's questions can assist the process.

Three assumptions may preclude the contribution of summative self assessment in higher education according to McDowell and Sambell (1999):

11 Journal of Practice Teaching 6(3) 2005, pp.8-30

(C) 2005 Whiting and Birch 
- Students are not sufficiently knowledgeable about assessment to comment

- Students may not recognise or assess appropriately the purpose of assessment

- Since students are being judged or tested their views are not sufficiently objective

These misconceptions hold true for practice teaching also. McDowell and Sambell's research found, however, that students generally prefer assessment to be interesting and challenging as a vehicle for learning rather than easy to pass. What students did want in assessment is to be engaged in the learning process, to receive feedback to enhance future learning, and to know clearly, what is expected. This provides an important counterbalance to the notion that students will simply pass themselves and it must be remembered that in practice learning self-assessment in the form of a critical evaluation of learning is fairly common as a constituent part of the process. Fitzpatrick examined selfassessment as a component of a nursing programme module, evaluating the potential for integrating professional knowledge with personal self-reflection and development. It is important that practice teachers are aware of this research, the assumptions relating to self-assessment and acknowledge it in their work with students. Of course, it is not the case that all students seek challenging learning experiences and act with such good intentions and an element of safety in assessment is necessary. This is achieved within practice learning in respect of triangulation of evaluation and assessment (see figure 1). This notwithstanding, a central assumption must be that accepting that a student is able to self-assess implies that students wish to improve their practice and will undertake the process in an honest way. Assessment in practice learning can be seen along a continuum of loci of control with external elements necessary to the degree and academic learning for professional practice to internal elements of personal readiness and evaluation which interlinks with the development of reflective practice and self-awareness (see figure 2) 
Figure 2

Loci of control in practice learning

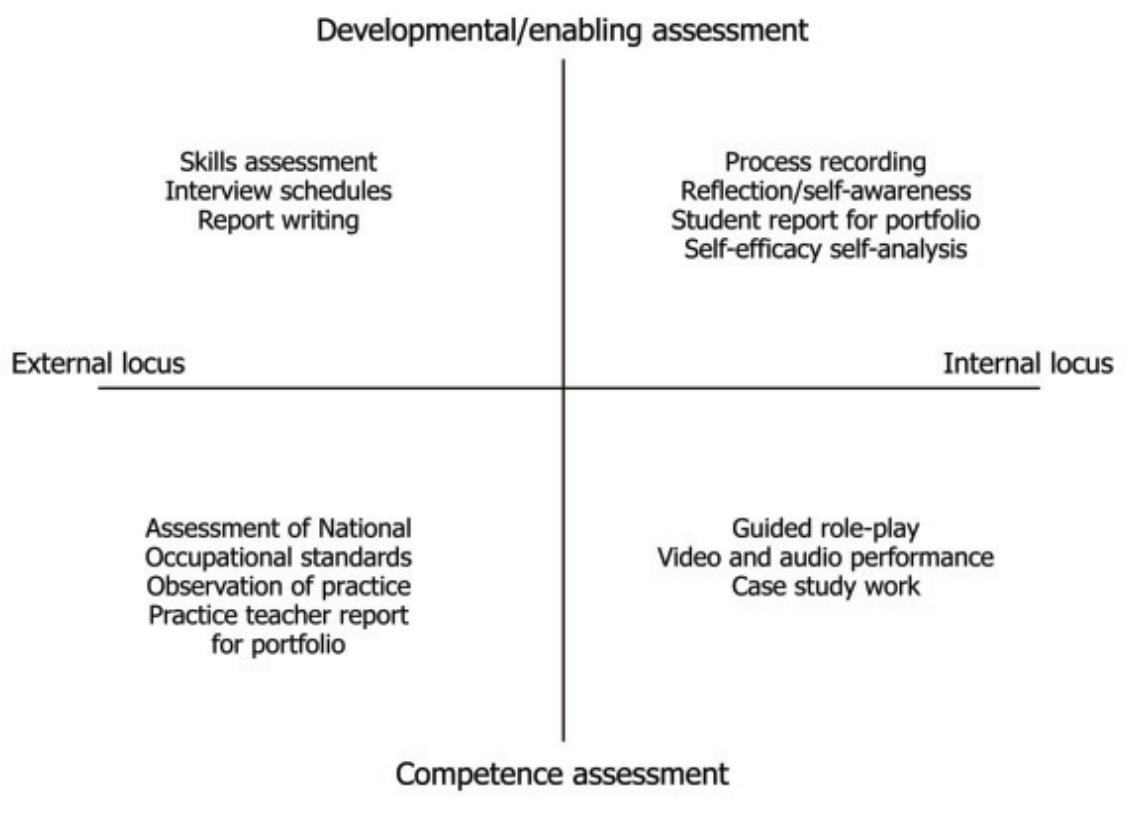

\section{Practice teachers and the assessment process}

If practice learning is purely focused on the final assessment outcome, this may become the crux of the experience which may reduce the level of learning and skills development (Wakeford, 2003). Therefore, finding ways that encourage students to engage fully with the experience, growing in knowledge, skills and values as social workers, and, indeed, about the self is crucial to an effective practice teaching role. It is important, therefore, to see the assessment of practice learning as a process of development facilitated rather than conducted solely by practice teachers.

A process model, where assessment is continuous, considers developmental issues and changes and takes into account the changing and mediated views of students and others involved in the assessment process. Such an approach prepares students for continuing development and learning required by the GSCC (2002; 2005). This is similar

13 Journal of Practice Teaching 6(3) 2005, pp.8-30 (C) 2005 Whiting and Birch 
to inculcating the development of a constant reflective cycle towards practice and will benefit from guided or focused supervision (Kolb, 1984; Boud and Walker, 1998; Parker, 2004). It is important to be aware of some of the complexities involved in encouraging and assessing reflective learning (Ixer, 1999). Developing a reflective approach, however, may contribute to the final, summative assessment of competence which generally results in two related and often integrated outputs - a practice teacher report and student report possibly collated within a portfolio. The portfolio relies heavily on practice teacher facilitated self-assessment as a process. Indeed, part of the evaluation of the portfolio is an assessment of the self-analytic and reflective abilities of the student and whether they can critically examine their practice in an open and emotionally intelligent way (Goleman, 1996).

The student perspective in assessment has been little considered but is central to the experience. Knight (2003) reports on a qualitative study of final year undergraduate students from an occupational therapy background, investigating their experiences of being assessed. She found high levels of acceptance with the primary assessment but some concern about its reliability, which demanded clear explanation of the assessment criteria for practice learning experiences and an indication of ways in which the criteria might be met. One way in which greater engagement and transparency may be gained is by promoting the triangulation of modes of assessment and encouraging self-assessment.

Practice learning opportunities need to be 'fit for purpose' and offer sufficient learning opportunities to meet the standards and requirements for social work practice. The process, and preparation for it, begins when negotiating the practice learning agreement and identifying opportunities to enhance knowledge and skills and assist in meeting some of the standards. It is important to assess the worth of the learning opportunities from a range of perspectives, one of which must be the students' understanding of their competence and learning needs. It is the student's learning and practice that is assessed during practice learning. The assessment will be specific to each practice agency but is likely to focus on the National Occupational Standards and the value base of social work. It is important to consider what evidence might be used to demonstrate learning in practice.

14 Journal of Practice Teaching 6(3) 2005, pp.8-30

(C) 2005 Whiting and Birch 


\section{Evidence and evaluation in the assessment process}

'Evidence-based practice' is central to the development of contemporary social work (Bilson, 2005). D'Cruz and Jones (2004) suggest that this may be understood as irrefutable evidence of effectiveness of certain types of practice and provides credibility for the social work profession. However, questions need to be considered as to whether a comprehensive evidence base can be generated to inform practice and who decides what constitutes evidence. D'Cruz and Jones (2004) believe that the political and ethical aspects involved in generating evidence must be taken into account when assessing it. We need not be too restrictive in determining what counts as evidence and recognise with SCIE (Pawson et al, 2003) that reflective practitioner knowledge, service user comment and views are equally valid forms of evidence alongside empirical observations of, in this case, a student's practice.

Wherever possible practice learning assessments should be evidenced-based drawing on a range of knowledge bases including the views of others in the agency, the practice teacher, service users, and research into practice and skills development in that area (Pawson et al., 2003). They should be able to show the facts relating to practice and link these to specific criteria for assessment. However, there will necessarily be a degree of interpretation in the assessment, especially when applying a judgement concerning how well a task is performed. This indicates that there is an unequal power balance in the relationship between student and practice teacher who is responsible for developing these interpretations and in turn making a recommendation concerning student suitability. This aspect of the relationship should be openly acknowledged. One way of addressing this is to use Wakeford's criteria (2003) for evidence. Evidence should:

- be clear

- promote learning

- be measurable

- be appropriate

- be consistent and rigorous

- contain evidence of moderation

It is important to consider ways in which students contribute to the assessment process and outcome and what opportunities there are for

15 Journal of Practice Teaching 6(3) 2005, pp.8-30 $\quad$ (C) 2005 Whiting and Birch


self-assessment. Introducing an element of self-assessment into the supervision process can assist here with students encouraged to reflect on the following questions:

- What aspects of my learning can I check with my practice teacher or assessor?

- What evidence will contribute to my final assessment and how might I present this effectively?

- What learning can I take forward into new situations?

Even where the evidence at first sight seems clear and based on actions, roles and tasks undertaken, there is a degree of interpretation involved in linking it to specific standards in the assessment. One of the roles of practice teaching is to encourage and assist students in gathering evidence from a wide range of sources, which may include:

- Letters, case records, reports

- Notes relating to presentations made to team meetings or colleagues

- Feedback from colleagues on presentations made

- Feedback from colleagues on work undertaken in the office or jointly on visits

- Observations of practice

- Discussions within supervision

- Feedback from service users and carers

- A work record

- Reflective journal or diary.

The evidence should be related to specific learning objectives and it is helpful to discuss the process within supervision. One question that concerns many students and, indeed, qualified social workers is, "how do I know the evidence is appropriate?' The SCIE quality standards framework for social care knowledge uses the acronym TAPUPA to interrogate evidence, asking questions about transparency, accuracy, purposivity, utility, propriety and accessibility (Pawson et al., 2003). It is useful to check evidence against the following criteria, similar in many ways to TAPUPA, but developed specifically for practice learning (Parker, 2004, pp. 96-97):

16 Journal of Practice Teaching 6(3) 2005, pp.8-30

(C) 2005 Whiting and Birch 
- Is it valid?

Does the evidence relate specifically to a requirement included in the practice learning agreement and does it demonstrate use of agency policy, procedure and practice?

- Is it sufficient?

Has the evidence been seen frequently enough to justify the assessment and is it of sufficient depth?

- Is it relevant?

Does the evidence relate specifically to the standard being considered or does it cover it in part or not at all?

- Is it based in social work values?

Does it reflect anti-oppressive values and promote a value-based approach to social work.

- Is it reliable?

Does the evidence build a consistent picture when taken together with other evidence from a range of sources?

- Is it clear?

Can the description of the evidence and the evidence itself be understood by others to relate to an assessed objective?

- Is it agreed?

Has the relevance and interpretation of the evidence been agreed by all involved, yourself as student, practice teacher, colleagues, service users and carers?

Students, in general, wish to enhance their learning by assessment and are able to gain from self-assessment activities which interlink with social work's emphasis on the development of critical self-awareness and reflective learning. Practice learning is assessed in a variety of ways taking into account the views of all stakeholders, including students. It is important, therefore, that ways of developing helpful and robust approaches to self-assessment are found.

17 Journal of Practice Teaching 6(3) 2005, pp.8-30

(C) 2005 Whiting and Birch 


\section{Self-efficacy as a means of promoting self-assessment}

Assessing self-efficacy represents an important way for developing effective student self-assessment in practice learning. The concept derives from the work of social learning theorist Albert Bandura (1977; 1986) concerning social cognitive theory. A theory of triadic reciprocal causation is central and suggests that personal factors, behaviours and environmental events interact and influence one another in the development of human behaviour and learning (Pajares, 2002). This model provides a way of understanding differential performance by social work students dealing with similar practice events and situations and offers students themselves an opportunity to identify ways of assisting the learning process by building on constructive experiences and self-efficacy beliefs. The basic premise of self-efficacy suggests that whilst a student may know what actions need to be undertaken in order successfully to execute a particular task (outcome expectations), there needs to be an element of confidence in one's ability to perform those actions in order to achieve effective completion (efficacy expectations) (Bandura, 1986). These 'efficacy expectations' lie at the heart of self-efficacy, which Holden et al $(2002,116)$ suggest is related to self-awareness but differs from self concept or self-esteem which is more global:

Self-efficacy is more than a self-perception of competency. It is an individual's assessment of his or her confidence in their ability (to) execute specific skills in a particular set of circumstances and thereby achieve a successful outcome.

\section{Self-efficacy and practice learning}

If self efficacy is less related to actual fact than belief, we may ask why is it useful in considering student beliefs about social work practice, which may or may not reflect their actual levels of competence? A strong confidence in the ability to do something tends to be associated with seeing challenges as things to be mastered rather than threats to be avoided and this, in turn, increases a commitment to goal achievement and persistence in the face of failure (Bandura, 1994). This suggests that a strong belief in the ability to perform social work tasks will lead to persistence and commitment and an active focus on the achievement of

18 Journal of Practice Teaching 6(3) 2005, pp.8-30 C 2005 Whiting and Birch 
A guided self-efficacy approach to practice learning assessment

desired goals. The corollary of this is that students who have low selfefficacy may not perform well during practice learning and will need a greater level of support to succeed, or may counsel themselves away from a career in social work choosing a different option more suited to their needs. This is important to practice learning and encouraging students to identify and negotiate opportunities to meet learning needs.

Experience of past achievements and identification of the processes involved is one source of these beliefs, as is the observation of proficient models. In respect of practice learning, this indicates the importance of prior experiences. Modelling processes are also important such as the 'shadowing' of social workers and the value of observational learning for students, all of which can be used to construct effective outcomes. Practice teachers may also use verbal encouragement to raise people's beliefs in their abilities to perform a task or role successfully to back up modelled practice and structured situations of success, whilst noticing students' physical and emotional states and reducing stress reactions. Practice teachers can use the concept to develop self-efficacy by reinforcing goal achievement.

A cultural issue arises in respect of self-efficacy that may impact on its use, its attraction and whether or not it can be used to (self)assess developing practice competence. Self-efficacy as a concept developed in the US where self-belief and confidence in promoting one's own competencies is much more celebrated than in many contemporary UK cultures. Different cultural variants may be an important source of difference in the use or attraction of self-efficacy scales. Beliefs in competence, however, are not necessarily over-confidence, naivety or arrogance, or indeed indicative of misguided beliefs about fitness to practise, rather they can be a tool that students can use to reach their potential, and to know what has to be achieved and that they can successfully execute what needs to be done. Using self-efficacy beliefs can provide valuable insight into one's perceptions of strengths and skills that can be jointly tested with the practice teacher throughout practice learning. This is where the value of the concept lies. People with high self-beliefs are usually able to visualise success scenarios which provide support for persistent performance. Failures in achievement, by these people, may be put down to insufficient effort as opposed to a lack of ability and therefore enhance and sustain motivation to try again. The individual who has high self-efficacy beliefs is less likely to avoid challenging situations or those which place them under some degree

19 Journal of Practice Teaching 6(3) 2005, pp.8-30 $\quad$ (C) 2005 Whiting and Birch 
of pressure. The importance of self-efficacy theory is that people with a high belief persevere and can endure obstacles and setbacks. When such people make errors in self-appraisal it is usually to over-estimate their capabilities. This can be construed as beneficial. If people's beliefs only reflected what they do routinely, they would lack aspirations and effort to achieve higher goals. If we apply this to practice learning, we may posit that those students with a high degree of self-belief will be able to tackle novel and challenging experiences and to be resolute in their pursuit of learning. Also, practice teachers can build coping skills within less confident students by modelling actions to show how threats can be dealt with and to allay fears, breaking down tasks into manageable sub-tasks and performing actions together with the student.

The value of using self-efficacy measures was shown in a study of students undertaking practice learning (Parker, 2005). Participation was voluntary, by informed consent. Twenty-five students agreed to participate in the study and 23 students completed, consisting of 19 females (76\%), and six males. The students' ages ranged from 20-49 years with the majority aged between 20 and 29 years, 17 (68\%) The students in the study had wide-ranging experience in social and health care prior to undertaking qualifying social work education.

Students taking part in the study were given a questionnaire to complete during the first two weeks of practice learning and again during the final two weeks (see appendix 1 for the questionnaire). The questionnaires were self-administered, completed anonymously but matched at pre- and post-test, and returned by a student organiser from the group. The scale asked students to indicate how confident, on a scale of one to five, they felt about 47 separate items representing a range of core areas for social work practice reflecting also some of the elements of the National Occupational Standards. Six domains of practice were identified. These included confidence in working with different service user groups and individuals, being able to establish relationships, being able to deal with the written requirements of practice, working with other professionals, developing professional and reflective practice, and looking after oneself.

The findings indicated that changes were occurring throughout practice learning in the level of the students' self-belief in their competence across these six domains. The least increase in mean confidence occurred in the area of personal resilience and coping with the stress of the job whilst the greatest increase occurred in the area concerning

20 Journal of Practice Teaching 6(3) 2005, pp.8-30 C 2005 Whiting and Birch 
the formation of interpersonal relationships, closely followed by written communication skills. Data were analysed and changes in the scores for each of the six domains of practice were significant indicating that they are unlikely to have occurred by chance and that internal reliability of the sub-scales was high. This suggests that undertaking practice learning leads to an increase in levels of self-confidence in one's abilities to practise, thus providing some justification for the increased attention to practice learning in the new qualifying awards in the UK. The significant changes in perceived self-efficacy throughout the placement suggest that practice learning is integral to the development of practitioners who perceive they have the competence to achieve the required outcome to complete tasks or make a difference. This is something that may be considered central to continued motivation for good practice (Bandura et al, 2001), and is key to the provision of appropriate support into the future for people who use social work services. The study was, however, limited and it is not certain that the changes resulted from the placement itself or, if they did, what learning experiences or structures led to these outcomes and how they worked.

The wider importance of using such scales is in initially identifying learning needs and areas for development and negotiating learning opportunities and support as part of the learning agreement made prior to the practice learning experience. Students can be encouraged to assess their own levels of self-efficacy and construct learning experiences and objectives around the results. These can be reviewed at various points throughout the practice learning opportunity. This is where the practice teacher role may be very useful in negotiating opportunities and challenges according to perceived levels of self-efficacy and adjusting these as necessary throughout the practice learning opportunity. The continued use of the scale in measuring the development of perceptions of self-efficacy can help refine the experiences throughout and can assist students' critical reflection on their learning. Whilst stronger students could be given challenges to stretch and develop their competence, it may also be possible to assist students with lower levels of self-belief to tackle manageable tasks and thus increase their perceptions of competence in a way that enhances perceptions of their ability. When a student is finding learning and doing difficult during practice learning, an exploration of their self-efficacy beliefs may identify barriers to successful performance or, in certain circumstances, indicate that the student is not at this time ready for social work practice or pursuing the wrong career path for

21 Journal of Practice Teaching 6(3) 2005, pp.8-30 @ 2005 Whiting and Birch 
Figure 3

A model for encouraging self-assessment

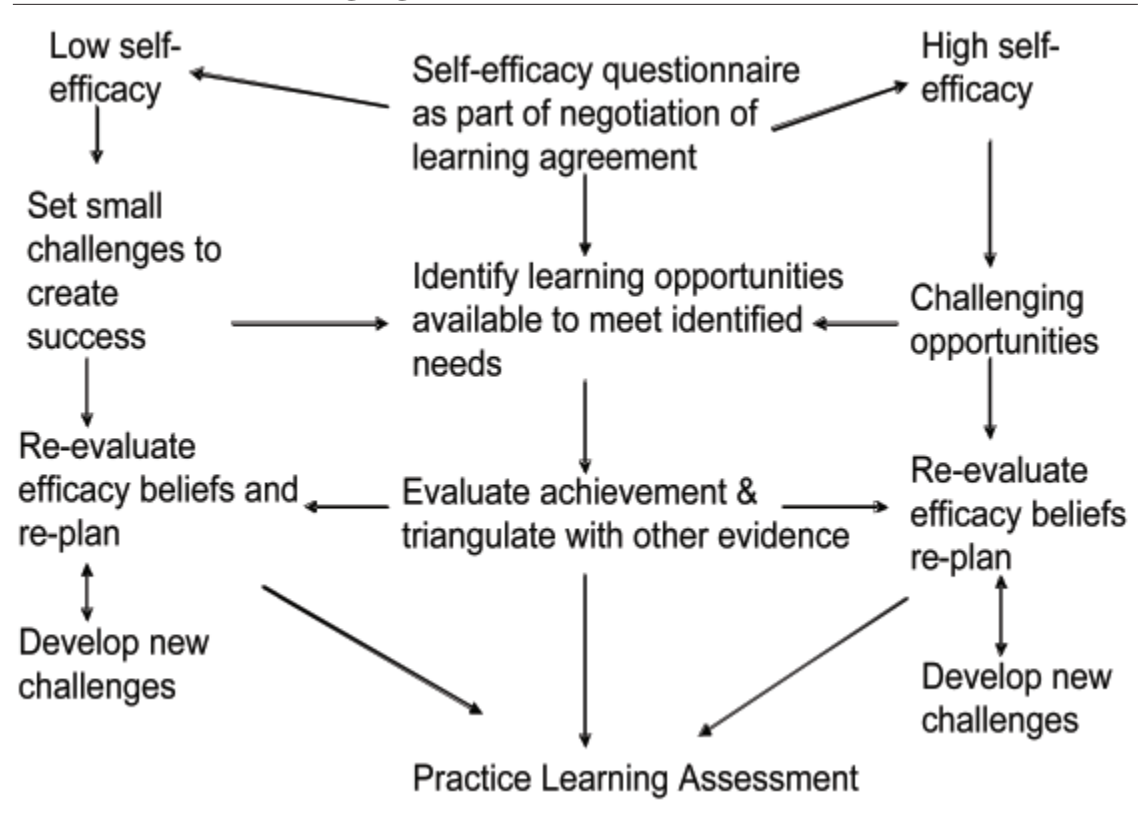

them. These outcomes are equally valid and being able to assist students to make appropriate choices is important for the future of the workforce and the safety of service users and carers. Figure 3 shows a model for using self-efficacy in student self-assessment.

A continuing issue in practice learning concerns the integration of theories and models in practice. Research indicates that the integration of theory into practice is associated with positive practice learning experiences (Regehr et al., 2002) or dissatisfaction where this is perceived to be inadequate (Marsh and Triseliotis, 1996). The self-efficacy scale can play a part in measuring the effectiveness of an increase in self-efficacy in using theories and models in practice and, therefore, may assist students in identifying their own learning needs and a basis from which to develop and negotiate a learning plan. Parker (2005) argues that the self-efficacy scale allows practice teachers to identify perceived strengths and weaknesses with individual students and provides opportunities to explore past experiences and perceptions of these and important contextual information. In a constructive student learning experience in which planned and structured goals and tasks, clear expectations, opportunities for observation and developing autonomy are prized 
within a supportive relationship (Bogo et al., 2002; Bogo et al., 2004; Regehr et al., 2002), the concept of self-efficacy could be usefully employed by students in identifying learning needs and negotiating learning opportunities in applying theories in practice.

It may happen that a student scores themselves lower at post-test than on the pre-test. This does not necessarily de-value the use of the scale and may reflect more the student's growing understanding of the complexities of the role and tasks involved in social work. One way of checking that this response-shift bias is controlled for is to undertake a retrospective 'then-test' that asks students to rate how confident they thought they were at the outset.

\section{In summary}

Student social workers can adequately assess their own self-efficacy, identify learning needs, development, and capacity for practice. The implications are that identification of self-efficacy beliefs will have two important roles. Firstly, they allow students to identify areas of practice they feel comfortable in and those they are less comfortable in, which, in turn, allow practice teachers to negotiate learning opportunities to meet identified needs. It then provides the opportunity to assess self-understanding and to challenge where discomfirmatory evidence is found. As Doel and Shardlow (2005, p. 32) state in respect of developing self-knowledge:

It is the outcome of this process which is assessed; in other words, how your growing self-knowledge influences your values and practice.

Self-assessment, and the use of a self-efficacy scale, is not the sole element of practice learning assessment to emphasise but represents an important tool to assist the process. A further use of the model is that differing perceptions of outcomes and competence can be highlighted and debated in the context of a pre- and post-test application of a self-efficacy questionnaire against practice teacher and student self assessment. This provides evidence towards the final evaluation and review which is, necessarily, a multiple stakeholder task.

23 Journal of Practice Teaching 6(3) 2005, pp.8-30

(C) 2005 Whiting and Birch 


\section{References}

Bandura, A. (1977) Self-efficacy: Toward a unifying theory of behaviour change. Psychological Review, 84, 191-215

Bandura, A. (1986) Social Foundations of Thought and Action: A social cognitive theory. Englewood Cliffs, NJ: Prentice-Hall.

Bandura, A. (1994) Self-efficacy. in V.S. Ramchandran (Ed.) Encyclopaedia of Human Behavior. Vol. 4. New York: Academic Press, pp. 71-81.

Bandura, A., Barbaranelli, C., Caprara, G., and Pastorelli, C. (2001) Self-efficacy beliefs as shapers of children's aspirations and career trajectories. Child Development, 72, 1, 187-206.

Bilson, A. (Ed.) (2005) Evidence-based Practice and Social Work. London: Whiting and Birch.

Bogo, M., Regehr, C., Hughes, J., Power, R., and Globerman, J. (2002) Evaluating a measure of student field performance in direct service: Testing reliability and validity of explicit criteria. Journal of Social Work Education, 38, 3, 385-401.

Bogo, M., Globerman, J., and Sussman, T. (2004) The field instructor as group worker: Managing trust and competition in group supervision. Journal of Social Work Education, 40, 1, 13-26.

Boud, D., and Walker, D. (1998) Promoting reflection in professional courses; The challenge of context. Studies in Higher Education, 23, 2, 191-206.

D'Cruz, H., and Jones, M. (2004) Social Work Research: Ethical and political contexts. London: Sage.

Department of Health (2002) Requirements for Social Work Training. London: Department of Health.

Doel, M. and Shardlow, S.M. (2005) Modern Social Work Practice: Teaching and learning in practice settings. Aldershot: Ashgate.

Edwards, C. (2003) The involvement of service users in the assessment of Diploma in Social Work students on practice placements. Social Work Education, 22, 4, 341-349.

GSCC (2002) Codes of Practice for Employees and Employers. London: General Social Care Council.

GSCC (2005) Post-Qualifying Framework for Social Work Education and Training. London: General Social Care Council.

Goleman, D. (1996) Emotional Intelligence. London: Bloomsbury.

Holden, G., Meenaghan, T., Anastas, J., and Montrey, G. (2002) Outcomes of

24 Journal of Practice Teaching 6(3) 2005, pp.8-30

(C) 2005 Whiting and Birch 
social work education: The case for social work self-efficacy. Journal of Social Work Education, 38, 1, 115-33.

Ixer, G. (1999) There's no such thing as reflection. British Journal of Social Work, 29, 4, 513-27.

Knight, J. (2003) Assessment of fieldwork practice: The student experience. Journal of Practice Teaching in Health and Social Work, 5, 1, 39-60.

Kolb, D.A. (1984) Experiential Learning. Englewood Cliffs, NJ: Prentice-Hall.

Marsh, P., and Triseliotis, J. (1996) Social Workers and Probation Officers: Their training and first year in work. Aldershot, Avebury.

McCafferty, P. (2004) Group supervision for social work students on placement. Journal of PracticeTeaching in Health and Social Work, 5, 3, 55-72.

McDowell, L., and Sambell, K. (1999) Fitness for purpose in the assessment of learning: Students as stakeholders. Quality in Higher Education, 5, 2, 107-123.

Pajares, F. (2002) Overview of Social Cognitive Theory and of Self-Efficacy. accessed February, 14, 2005 from http://www.emory.edu/EDUCATION/mfp/eff. html

Parker, J. (2004) Effective Practice Learning in Social Work. Exeter: Learning Matters

Parker, J. (2005) Developing perceptions of competence during practice learning British Journal of Social Work, Advanced Access Publication, 17 Oct 2005. http://bjsw.oxfordjournals.org/cgi/reprint/bch347?ijkey=j0v3DZ dwH3NvcHZ\&keytype=ref

Parker, J. (forthcoming) Developing practice learning for tomorrow's social workers. Social Work Education

Parker, J., Whitfield, J., and Doel, M. (2006) Improving Practice Learning in Local Authorities (2). Workforce Development, Recruitment and Retention. Capturing the Learning Series. Leeds: Skills for Care.

Pawson, R.,Boaz, A., Grayson, L., Long, A., and Barnes, C. (2003) Types and Quality of Knowledge in Social Care.Knowledge Review 3, London: SCIE.

Ramsden, P. (2003) Learning to Teach in Higher Education.(2nd ed) London: Routledge Falmer.

Regehr, C., Regehr, G., Leeson, J., and Fusco, L. (2002) Setting priorities for learning in the field practicum: A comparative study of students and field instructors. Journal of Social Work Education, 38, 1, 55-65.

SCIE (2004) Learning Organisations: A self-assessment resource pack. accessed November 2005, from http://www.scie.org.uk/publications/learningords/ index.asp

Thomas, R. (2002) Creative assessment: Involving service users in student

25 Journal of Practice Teaching 6(3) 2005, pp.8-30

(C) 2005 Whiting and Birch 
assessment in social work. Journal of Practice Teaching in Health and Social Work, 4, 1, 27-43.

Wakeford, R. (2003) Principles of student assessment. in H. Fry, S. Ketteridge, and S. Marshall (Eds.) A Handbook for Teaching and Learning in Higher Education: Enhancing academic practice. (2nd ed) London: Kogan Page, pp.42-61.

Watkins, M., and Edwards, J. (2002) Reflections on an attempt to improve the preparation of social work practice teachers. Journal of Practice Teaching in Health and Social Work, 4, 2, 7-27. 


\section{Appendix 1}

\section{SELF-EFFICACY AT WORK}

This form is designed to gain an insight into how confident you feel at the time of completion of dealing with the situations described. I will ask you to complete a form at the outset to your placement and one towards the end. This will help to identify any changes and development in your confidence.

Thank you for your time in completing this questionnaire. You will not be identified from any responses given and the form is for research purposes not to identify need or to assess learning. Completion is voluntary and you may withdraw at any time.

About You (Please circle those that apply to you)

\begin{tabular}{lrrr} 
Male & \multicolumn{3}{c}{ Female } \\
Age & $20-24$ & $25-29$ & $30-34$ \\
& $35-39$ & $40-44$ & $45-49$ \\
& $50-54$ & $55-59$ &
\end{tabular}

If you have worked in social or health care it would be helpful if you indicate with which client groups you have worked : 


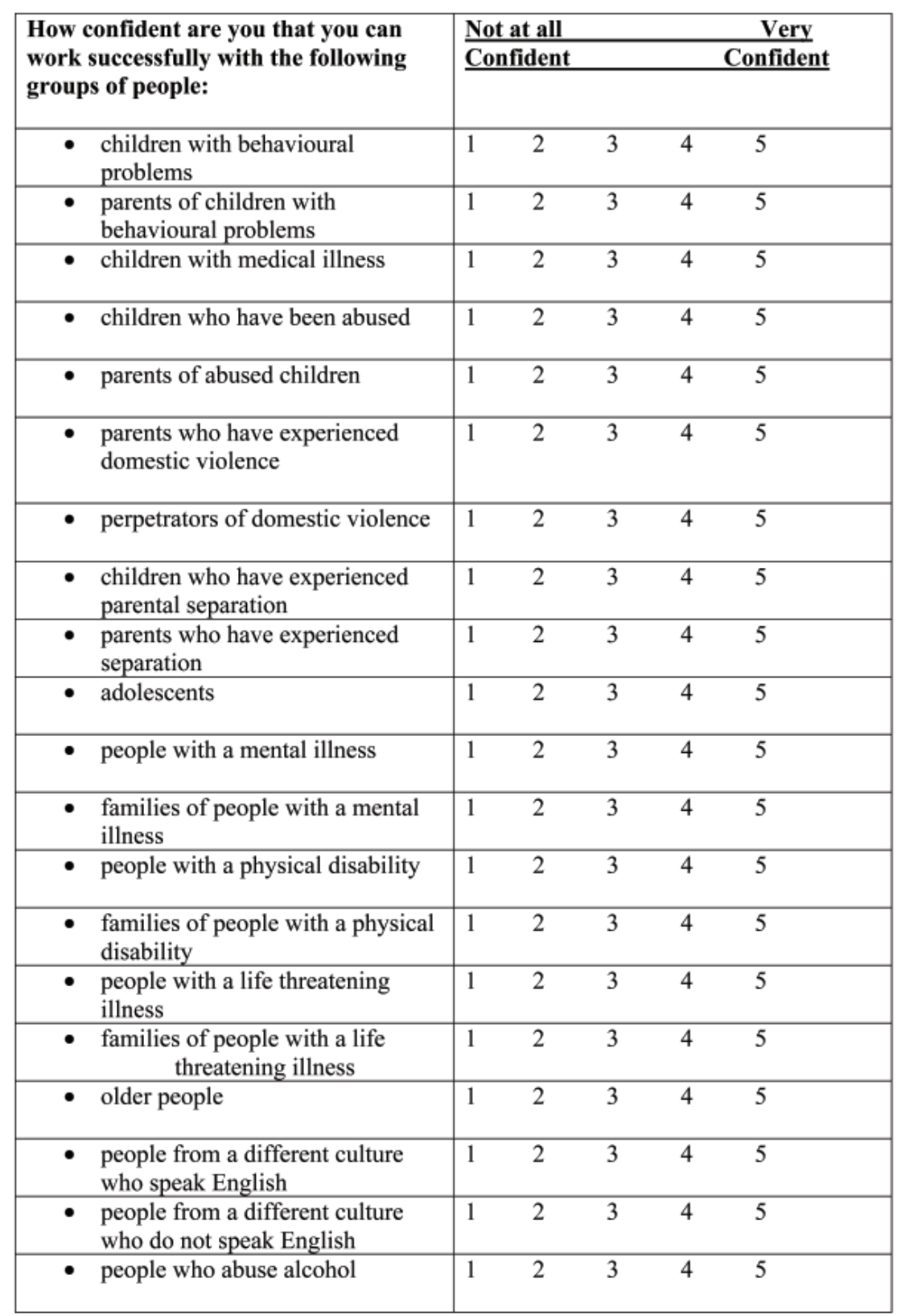


A guided self-efficacy approach to practice learning assessment

\begin{tabular}{|c|c|c|c|c|c|}
\hline $\begin{array}{l}\text { - people who abuse substances } \\
\text { other than alcohol }\end{array}$ & 1 & 2 & 3 & 4 & 5 \\
\hline $\begin{array}{l}\text { - people who are loud, threatening, } \\
\text { abusive or violent }\end{array}$ & 1 & 2 & 3 & 4 & 5 \\
\hline \multicolumn{6}{|l|}{$\begin{array}{l}\text { How confident are you that you can } \\
\text { successfully: }\end{array}$} \\
\hline - establish contact with clients & 1 & 2 & 3 & 4 & 5 \\
\hline $\begin{array}{l}\text { - form working relationships with } \\
\text { clients }\end{array}$ & 1 & 2 & 3 & 4 & 5 \\
\hline $\begin{array}{l}\text { provide relevant information and } \\
\text { advice }\end{array}$ & 1 & 2 & 3 & 4 & 5 \\
\hline - collect relevant information & 1 & 2 & 3 & 4 & 5 \\
\hline \multicolumn{6}{|l|}{$\begin{array}{l}\text { How confident are you that you can } \\
\text { successfully: }\end{array}$} \\
\hline $\begin{array}{l}\text { - write clear, explanatory and } \\
\text { informative letters to clients }\end{array}$ & 1 & 2 & 3 & 4 & 5 \\
\hline $\begin{array}{l}\text { - write comprehensive, informative } \\
\text { and relevant case notes }\end{array}$ & 1 & 2 & 3 & 4 & 5 \\
\hline $\begin{array}{l}\text { write comprehensive, informative } \\
\text { and relevant assessment reports }\end{array}$ & 1 & 2 & 3 & 4 & 5 \\
\hline \multicolumn{6}{|l|}{$\begin{array}{l}\text { How confident are you that you can } \\
\text { work successfully with: }\end{array}$} \\
\hline - other social work students & 1 & 2 & 3 & 4 & 5 \\
\hline - other social work staff & 1 & 2 & 3 & 4 & 5 \\
\hline - your supervisor/practice teacher & 1 & 2 & 3 & 4 & 5 \\
\hline - administrative staff & 1 & 2 & 3 & 4 & 5 \\
\hline - other agency staff & 1 & 2 & 3 & 4 & 5 \\
\hline - teachers & 1 & 2 & 3 & 4 & 5 \\
\hline - health visitors & 1 & 2 & 3 & 4 & 5 \\
\hline $\begin{array}{l}\text { - social workers external to the } \\
\text { agency }\end{array}$ & 1 & 2 & 3 & 4 & 5 \\
\hline
\end{tabular}




\begin{tabular}{|c|c|c|c|c|c|}
\hline $\begin{array}{l}\text { How confident are you that you can } \\
\text { successfully: }\end{array}$ & & & & & \\
\hline $\begin{array}{l}\text { - apply theoretical models } \\
\text { appropriately }\end{array}$ & 1 & 2 & 3 & 4 & 5 \\
\hline - identify learning needs & 1 & 2 & 3 & 4 & 5 \\
\hline - evaluate your practice & 1 & 2 & 3 & 4 & 5 \\
\hline $\begin{array}{l}\text { - make plans to increase learning } \\
\text { opportunities }\end{array}$ & 1 & 2 & 3 & 4 & 5 \\
\hline $\begin{array}{l}\text { - recognise the ethical tensions } \\
\text { inherent in the work }\end{array}$ & 1 & 2 & 3 & 4 & 5 \\
\hline $\begin{array}{l}\text { How confident are you that you can } \\
\text { successfully: }\end{array}$ & & & & & \\
\hline $\begin{array}{l}\text { manage the stress that you will } \\
\text { feel in a fast-paced working and } \\
\text { learning environment }\end{array}$ & 1 & 2 & 3 & 4 & 5 \\
\hline $\begin{array}{l}\text { - manage the frustration you will } \\
\text { feel working with agency } \\
\text { bureaucracy }\end{array}$ & 1 & 2 & 3 & 4 & 5 \\
\hline $\begin{array}{l}\text { manage the feelings that you will } \\
\text { have working with clients } \\
\text { experiencing emotional and } \\
\text { psychological distress }\end{array}$ & 1 & 2 & 3 & 4 & 5 \\
\hline $\begin{array}{l}\text { manage the feelings you will have } \\
\text { when clients or their families } \\
\text { blame you for things going wrong }\end{array}$ & 1 & 2 & 3 & 4 & 5 \\
\hline $\begin{array}{l}\text { manage the feelings you will have } \\
\text { when team members from other } \\
\text { disciplines blame you for things } \\
\text { going wrong }\end{array}$ & 1 & 2 & 3 & 4 & 5 \\
\hline
\end{tabular}

